\title{
KEPEMILIKAN NUKLIR DAN KEAMANAN NASIONAL IRAN: SUATU STUDI KASUS
}

\author{
Obsatar Sinaga \\ Dosen Jurusan Hubungan Internasional FISIP UNPAD \\ Jl Raya Bandung Sumedang Km 21 Jatinangor-Sumedang \\ Email : oby_jabar@yahoo.com
}

\begin{abstract}
ABSTRAK. Peranan negara-bangsa (nation-states) dalam hubungan internasional masih memegang peranan yang penting, terutama dalam memenuhi kepentingan nasionalnya. Salah satu permasalahan penting yang selalu berhubungan dengan negara adalah mengenai keamanan. Tulisan ini memusatkan kajian pada kepemilikan nuklir Iran dalam konteks kerangka kerja analisis keamanan nasional. Dalam hal ini kepemilikan nuklir Iran merupakan salah satu upaya negara untuk bertahan hidup dan mendapatkan posisi tawar yang lebih baik dalam berinteraksi dengan negara-negara lain, khususnya menghadapi dominasi Amerika Serikat.
\end{abstract}

Kata kunci: Keamanan nasional, nuklir, negara-bangsa, kepentingan nasional, hubungan internasional.

\section{NUCLEAR OWNERSHIP AND NATIONAL SAFETY : A CASE STUDY OF IRAN}

ABSTRACT. The role of nation-states in international relations is very significant especially in fulfilling their national interests. One of crucial problem faced by nation-states is security. This essay is focused on Iran nuclear possesion with regard to framework for analysis of national security. In this respect, it is one of efforts of Iran to survive and to have a better bargaining position in interactions with other countries including in facing the US domination.

Key words: National security, nuclear, nation-states, national interests, international relations.

\section{PENDAHULUAN}

Sejak zaman dahulu, tinjauan mengenai aspek keamanan sudah mengemuka baik sebelum maupun sesudah perjanjian Westphalia ditandatangani oleh negarabangsa di kawasan Eropa (Baylis dan Smith, 2002: 36). Saat ini, masalah keamanan yang mengemuka dan menarik perhatian dunia adalah mengenai kepemilikan nuklir Iran.

Proyek nuklir Iran dituduh bertujuan tidak baik terutama oleh negara adikuasa yang memiliki kepentingan atas Timur Tengah. Media Barat begitu gencarnya menunjukan kekhawatiran mereka mengenai rencana nuklir ini. Hal ini dipengaruhi 
oleh pernyataan Presiden Amerika Serikat (AS), George Walker Bush, yang mengidentifikasi Iran sebagai poros kejahatan (axis of evi) yang memberikan tantangan bagi perdamaian dunia.

Meskipun masalah ini adalah masalah domestik Iran, tetapi dunia internasional memberikan perhatian lebih kepadanya. Hal itu sesuai dengan pendapat Kegley (2004) yang menyatakan, bahwa karena globalisasi masalah domestik biasa menjadi masalah internasional atau lebih dikenal dengan istilah intermestic. Masalah nuklir Iran adalah masalah domestik yang juga menjadi masalah internasional dan melibatkan tidak hanya Iran saja.

Di lain pihak proyek nuklir merupakan salah satu tujuan Presiden Iran, Mahmoud Ahmadinejad, untuk lebih fokus kepada masalah dalam negeri Iran. Pengayaan uranium di Isfahan merupakan bentuk konkrit dari apa yang Ahmadinejad janjikan yaitu upaya peningkatan kesejahteraan dan pengurangan kemiskinan. Pada saat ini, proyek yang sudah mengalami banyak kemajuan bisa dilihat dari pembangunan yang terdapat di empat tempat utama yaitu Bushehr, Isfahan, Natanz, dan Arak (The Economist, 2008: 30). Diharapkan keamanan nasional Iran akan didapatkan dengan adanya proyek nuklir tersebut.

Proyek nuklir ini mendapat tentangan dari berbagai negara termasuk Euro3 (Prancis, Jerman, dan Inggris) dan Amerika Serikat. Negara-negara ini percaya, bahwa dengan adanya proyek nuklir Iran akan mengganggu stabilitas keamanan di wilayah Timur Tengah. Iran sendiri bergeming dan tetap bersikukuh bahwa proyek ini untuk tujuan damai. Selain itu pada tahun 1977 pada saat proyek nuklir akan dijalankan tidak terdapat tentangan dari negara-negara tersebut (Kartini, 2005: 9).

Permasalahan nuklir Iran sangat menarik bagi penulis. Selain karena terus berkembang kita bisa menganalisa kasus ini lewat teori hubungan internasional yang penulis pelajari. Iran sendiri memiliki cadangan minyak terbanyak dunia setelah Arab Saudi dan cadangan gas terbanyak setelah Rusia (www.bbc.co.uk, 23 April 2007). Dilihat dari kepemilikan sumber daya alamnya, seharusnya Iran tidak perlu memiliki nuklir karena dengan bahan bakar konvensional (minyak bumi) sudah cukup. Tetapi pada kenyataannya Iran terus memacu mesin-mesin pengayaan nuklirnya.

\section{PERSPEKTIF KEAMANAN NASIONAL DALAM KEPEMILIKAN NUKLIR Keamanan (Security)}

Salah satu permasalahan esensial dalam hubungan internasional, terutama yang dibahas oleh kaum realis adalah mengenai keamanan (security). Menurut Stuart Croft (2006) keamanan adalah masalah yang menyangkut eksistensi sebuah negara dan pembahasannya banyak dibahas terutama oleh kaum neo-realis. Masalah keamanan ditangani oleh negara dan agennya seperti militer (Croft, 2006: 1).

Peter Hough mengatakan, bahwa definisi mengenai keamanan masih bersifat 'contested concept', atau sebuah konsep yang secara argumentatif menantang untuk ditemukan artinya (Hough, 2004:15). Sementara definisi yang paling sering 
digunakan oleh penstudi $\mathrm{HI}$ adalah definisi dari Barry Buzan yang dalam bukunya People, States, and Fear (1991) mengatakan bahwa, "security, in any objective sense, measures the absence of threat to acquired values, in a subjective sense, the absence of fear that such values will be attacked" (Buzan, 1991:4).

Keamanan merupakan suatu kondisi yang berkaitan dengan beberapa aspek lainnya dalam kehidupan manusia, tidak hanya persoalan-persoalan militer semata, tetapi juga meliputi persoalan politik, ekonomi, dan sosial budaya. Buzan mengklasifikasikan keamanan ke dalam lima dimensi, yaitu :

a. Dimensi militer, yang tidak hanya mengacu kepada pembangunan ketakutan militer baik konvensional maupun nuklir namun meliputi pula pengembangan kemampuan personil militer dan doktrin-doktrin kemiliteran.

b. Dimensi politik, yang merujuk pada upaya-upaya yang dilakukan oleh negara untuk menjaga dan mempertahankan kesinambungan proses politik, ideologi dan sistem pemerintahan.

c. Dimensi ekonomi, yang merujuk pada upaya-upaya melindungi sumber-sumber ekonomi dan kesejahteraan yang dimiliki negara

d. Dimensi sosial, yang mengacu pada kemampuan untuk melindungi nilai-nilai budaya bangsa

e. Dimensi lingkungan, yang merujuk pada upaya-upaya untuk melindungi dan memelihara lingkungan hidup sebagai pendukung utama kelangsungan hidup manusia (Buzan, 1991: 117-134).

Dari paparan diatas, dapat kita simpulkan bahwa sebenarnya aspek keamanan tidak lepas dari perspektif ancaman. Ancaman sendiri ditentukan oleh negara yang merasa terancam. Ancaman terhadap keamanan sendiri didefinisikan Ullman sebagai:

An action or sequence of events that (1) threatens drastically and over a relatively brief span of time to degrade the quality of life for the inhabitants of a state or (2) threatens significantly to narrow the range of policy choices available to government of a state, or to private, nongovernmental entities (persons, groups, corporations) within the state (Ullman, 1983:133).

Sebuah perspektif ancaman tidak akan lepas dari masalah keamanan. Luasnya masalah keamanan melahirkan banyak cakupan, salah satu derivasinya adalah mengenai keamanan nasional (national security) yang akan dibahas pada bagian selanjutnya.

\section{Keamanan Nasional (National Security)}

Meskipun merupakan derivasi dari security, keamanan nasional sendiri adalah sesuatu yang sulit untuk didefinisikan. Tetapi penggunaan istilah keamanan nasional dapat diartikan secara subjektif oleh penggunanya, seperti menurut spiegel (2004): 
National security is a modern incantation. As in any incantation the words have both power and mystery. In the name of national security, all things can be threatened. All risk can be taken. All sacrifices can be demanded... The ultimate catch-all term, it can mean anything the user chooses it to mean. (Spiegel, 2004: 402)

Dalam hubungan internasional, keamanan nasional adalah sebuah aspek yang signifikan yang merupakan awal tujuan negara untuk survive dalam sistem internasional. Perihal keamanan nasional muncul sejak konsep negara bangsa ada dan selalu menjadi topik yang penting bagi negarawan. Hal ini diamini oleh Spiegel yang menyatakan bahwa:

In many periods of history, national security was such as important value that people were expected to lay down their lives for it without question. The ancient roman had an expression for national security: "how sweet and beautiful it is to die for fatherland." Today, even as economic interdependence and globalization link people together, state nonetheless continue to devote vast resources to protecting their independence and their sovereignty. (Spiegel, 2004: 401)

Dari pengertian di atas kita bisa melihat, bahwa cakupan dari keamanan nasional sendiri sangatlah besar, sesuai dengan keinginan pelaksana dan pengemukanya. Jika dikaitkan dengan lima keamanan oleh Barry Buzan (1991), maka cakupan dari keamanan nasional bisa mencakup semuanya atau bahkan melebihinya.

Cakupan keamanan menurut Spiegel (2004) akan selalu melebar dan tidak akan pernah berhenti. Permasalahan seperti degradasi lingkungan, ketergantungan akan sumber daya alam yang semakin tinggi, tingkat pertumbuhan penduduk yang sangat tinggi, dan migrasi bisa mengancam keamanan nasional tanpa mengindahkan kekuatan ekonomi, politik, dan sistem sosialnya bisa mengarahkan negara kepada keadaan instabilitas yang bahkan bisa meruntuhkan negara tersebut (Spiegel, 2004: 402).

Meskipun cakupan keamanan nasional selalu berkembang dan melebar, Wolfers dalam Art dan Jervis (1985) melihat, bahwa sejatinya keamanan nasional adalah sebuah simbol kekuatan yang melindungi negara lewat power negara (national power). Hal ini kemudian ditambahkannya ketika mengatakan, bahwa kekuatan negara dapat membantu menghilangkan sebuah ancaman atau ketakutan akan sesuatu yang mengancam negara (Wolfers dalam Art dan Jervis, 1985: 43). Karena itu negara akan selalu mencari keamanan nasional dan selalu meningkatkannya.

Morgenthau dan Thompson (1985) mengatakan bahwa national power sangat penting dalam menjaga agar keadaan negara selalu stabil. Seperti yang diutarakan diatas oleh Spiegel (2004) mengenai ketentuan bagi deterrence seperti komitmen, 
kredibilitas, dan kapabilitas; national power sangatlah berhubungan dengan ketiganya. Bila negara kuat, maka ia akan memiliki kapabilitas yang kuat, kredibilitas yang disegani, serta komitmennya untuk menjaga agar negaranya aman.

Mengenai national power, Lieber menambahkan bahwa meskipun tidak menjamin kontrol maksimal dalam hubungan internasional, national power mampu melakukan empat hal, yaitu:

a. Menjamin otonomi atau kedaulatan yang dimiliki oleh sebuah negara agar tetap kuat dihadapan kekuatan yang dimiliki oleh negara lain.

b. Memberikan cakupan yang lebih luas mengenai tindakan apa yang akan dilakukan meskipun hasil tindakan tersebut belum jelas hasilnya.

c. Membuat marjin/jarak kekuatan dengan negara lainnya aman dan memberikan ketenangan kepada negara.

d. Semakin besar power negara dalam hubungan internasional maka akan memberikan taruhan yang besar dan kemampuan untuk bertindak dalam rangka kepentingan negaranya (Lieber, 1991: 13).

Negara akan lebih sensitif mengenai masalah keamanan nasionalnya apabila memiliki sejarah atau pengalaman perang baik diserang maupun menyerang negara lainnya. Negara yang sensitif tersebut selalu menemukan dirinya dalam sebuah keadaan yang mengancam negaranya (Wolfers dalam Art dan Jervis, 1985: 44). Dalam menjaga agar negara tetap selamat dalam hubungan internasional, Quinlan (1991) mengatakan bahwa keamanan nasional membutuhkan perasaan aman dari agresi negara asing. Kemudian ia menambahkan bahwa:

...our own country, is primarily to provide national security; that is, of helping to ensure that our citizen are free to lead their lives without unjustly constrained or oppressed through external military force, whether threatened or actual... But the issues of security must arise in relation to countries near enough, powerful enough, or positively or negatively important enough to us for their actions to be capable of seriously damaging us (Quinlan, 1991: 243).

Kapabilitas erat kaitannya dengan aspek militer, dan senjata nuklir menjadi determinan utama dari kapabilitas sebuah negara (Spiegel, 2004: 410). Kapabilitas negara sangatlah penting termasuk sebaik apakah kualitas persenjataan militer dan sebanyak apakah kuantitas personel militer yang dimiliki oleh negara yang bersangkutan. Kekuatan nasional yang kuat diharapkan mampu menjaga keamanan nasionalnya.

Dalam menunjang national power, terdapat sebuah aspek lainnya yang juga penting, yaitu geopolitik. Menurut Jablonsky dalam Bartholomees (2006), faktor geopolitik -dimana terdapat faktor geografi di dalamnya- menentukan kapasitas sebuah negara. Negara satu akan berbeda cara pandangnya terhadap ancaman terhadap keamanan nasional juga tergantung dari posisi negara yang bersangkutan. 


\section{Penangkalan (Deterrence)}

Teori berikutnya yang berhubungan dengan kapabilitas nuklir tentunya adalah deterrence. Pada awalnya teori ini digunakan untuk menjelaskan hubungan antara negara super-power dalam perang dingin yaitu Amerika Serikat dan Uni Soviet (Bartholomees Jr, 2006: 100). Setelah itu, penggunaan teori ini menjadi luas dan tidak hanya berhubungan dengan dua kutub negara setelah perang dingin berakhir.

Menurut Spiegel (2004) terdapat beberapa persyaratan yang harus dipenuhi sebuah negara agar deterrence bekerja, yaitu:

a. Komitmen

Sebagai langkah awal dari deterrence, negara harus memiliki komitmen akan "menghukum" negara lain yang berani melakukan serangan kepada negara yang bersangkutan. Dalam artian lain, negara yang berada dalam posisi bertahan harus dengan tegas membuat garis batasan dan memberi peringatan kepada negara yang menantangnya bahwa jika melewati garis batasan tersebut penderitaanlah yang akan dirasakan olehnya. Dalam menekankan komitmen negara, yang dibutuhkan adalah sebuah langkah yang definitif dan spesifik. Fungsi deterrence akan gagal jika negara bersikap ambigu dan tidak memiliki komitmen yang kuat untuk "menghukum" negara yang melakukan serangan.

b. Kapabilitas

Langkah kedua adalah komitmen yang jelas pun tidak akan berarti banyak jika negara tidak punya alat untuk melaksanakannya. Karena deterrence adalah meyakinkan negara lain bahwa melakukan kesalahan-seperti menyerang negara yang dalam posisi bertahan-maka negara haruslah memiliki kekuatan berupa kapabilitas untuk menyerang balik negara lawan. Bahkan jika tingkat deterrence terlihat lemah, negara harus terlihat meyakinkan musuhnya, bahwa ini bukanlah kekuatan keseluruhan yang dimilikinya.

c. Kredibilitas

Syarat terakhir adalah mengenai kredibilitas negara yang melakukan deterrence. Kredibilitas negara, masa lalu negara yang bersangkutan, dan gambaran umum mengenai negaranya membantu agar deterrence berhasil. Kredibilitas membantu negara dalam melaksanakan komitmen dan membangun kapabilitas agar meyakinkan negara lain tidak melakukan agresi kepada negara yang dalam posisi bertahan. Dengan kredibiltas ini dalam pikiran negara agresor, maka deterrence akan berjalan baik (Spiegel, 2004: 421-423).

Secara umum, pengertian deterrence adalah bagaimana membuat musuh takut untuk menyerang (Bartholomees Jr, 2006: 100). Alat-alat yang menunjukkan kapabilitas militer biasanya digunakan untuk membuat negara lainnya takut untuk melakukan serangan kepada negara yang memiliki kapabilitas yang kuat. Tetapi bagaimana bila sebuah negara tidak memiliki kapabilitas yang kuat untuk 
melakukan deterrence? Jawabannya bisa ditemukan lewat penangkalan nuklir (nuclear deterrence).

Seperti yang dikemukakan Waltz dalam Art dan Jervis (2000), negara kuat akan berpikir panjang dan cenderung ragu-ragu untuk menyerang negara lemah tapi memiliki nuklir. Memang jika negara memiliki nuklir, bahkan dari fasilitasnya saja, akan dianggap sebagai negara yang menganggung resiko yang kecil akan diserang negara lain. Resiko ini akan semakin berkurang jika pemerintahan yang memiliki nuklir secara kuat termotivasi untuk menjaga negaranya (Buzan, 1991: 169). Negara yang akan menyerang dipaksa untuk menanggung resiko yang besar jika meremehkan nuclear deterrence.

Mengenai senjata nuklir yang bisa digunakan, Quinlan (1991) memiliki pendapat yang sama dengan Gray (1986). Menurutnya, jika senjata nuklir memiliki peranan dalam pencegahan perang, maka mereka (senjata nuklir) haruslah operasional. Senjata nuklir bukanlah barang pajangan atau hanya sebuah simbol dalam bidak catur hubungan antar negara, senjata yang lemah tidak akan memberikan dampak power yang signifikan (Quinlan, 1991: 247).

Kesemua teori yang diutarakan penulis seperti deterrence, security, dan national security memiliki hubungan antara satu dengan lainnya dan tidak saling bertentangan. Keamanan nasional didapatkan bila negara mampu melindungi masyarakatnya dengan meminimalisir ancaman keamanan yang mungkin muncul. Cara penanganan penghilangan ancaman bisa dilakukan dengan menggunakan cara penangkalan (deterrence) yang idenya datang dari neo realisme.

\section{METODE}

Penelitian ini menggunakan metode kualitatif jenis studi kasus. Langkahlangkah yang harus dilakukan dalam penelitian kualitatif jenis studi kasus adalah (1) melakukan penentuan terhadap tipe kasus yang didasarkan pada banyaknya kasus single case atau collective case; (2) faktor lokasi dari kasus berupa multisited case atau within sited case; dan (3) fokus studi, apakah kasus memiliki sifat khusus (intrinsic case study) atau berfokus pada persoalan dari kasus itu sendiri dan menggunakan kasus sebagai pelengkap untuk menjelaskan persoalan tersebut (instrumental case study). (Creswell, 1998; 61-63). Penelitian ini didasarkan pada bentuk single case study karena hanya terdapat satu kasus yakni upaya pembangunan keamanan nasional Iran melalui kepemilikan nuklir dimana kasus ini merupakan within sited dan berupa instrumental case study karena kasus yang diangkat dalam penelitian ini merupakan pelengkap untuk menjelaskan hubungan internasional dalam system internasional yang anarki.

Teknik pengumpulan data yang digunakan adalah library research yang diperoleh dari sejumlah data sekunder seperti buku, artikel, jurnal, tulisan-tulisan ilmiah, surat kabar, dokumen resmi serta data-data dari media elektronik yang keseluruhan data sekunder tersebut dapat dipertanggungjawabkan dan berkaitan dengan bahasan yang diteliti. 


\section{HASIL DAN PEMBAHASAN \\ Iran dan Ancaman Keamanan Nasional}

Perasaan aman adalah sesuatu yang abstrak dan tidak terdefinisi, tetapi bisa dirasakan bila seseorang berada dalam sebuah lingkupan rasa aman. Hal ini sesuai dengan perkataan Spiegel (2004), bahwa dalam melihat masalah keamanan terdapat persepsi yang kuat dari perasaan. Maksudnya, keamanan bisa bersifat subjektif tergantung dari yang dirasakan si pemilik perasaan tersebut.

Hal di atas sesuai untuk menggambarkan bagaimana pandangan negara Iran akan persepsi tidak aman yang terjadi ketika dua negara tetangganya (Afghanistan dan Irak) di invasi oleh kekuatan politik dan militer yang lebih besar dari entitas Iran sendiri. Hal-hal yang biasa berubah menjadi tidak biasa ketika Iran harus mengubah tindakannya kepada negara tetangganya tersebut. Hal ini sedikit banyak menjelaskan kenapa Iran berhasrat memiliki nuklir.

Meskipun terlihat subjektif, bila dilihat dari sisi keamanan objektif kekhawatiran Iran akan keamanan nasionalnya cukup beralasan, hal ini sesuai dengan pendapat Chubin dan Litwak (2003) yang menyatakan bahwa:

Some Western observers, in an effort to remain impartial, have sympathized with Iran's quest for nuclear weapons, allegedly because the country is located in a rough, nuclearized neighborhood (with Israel and Pakistan) and because proximate U.S. military power, now extended into Iraq and Afghanistan, poses a threat to the country's security. Some of these same observers also argue that Iran's aspirations to develop nuclear weapons are not peculiar to this regime, given the shah's decision in the 1970 s to construct the Bushehr nuclear reactor. Viewed through this political prism, Persian nationalism is said to be the nuclear program's principal impulse (Chubin dan Litwak, 2003: 100)

Pendapat Chubin dan Litwak di atas memperlihatkan, bahwa terdapat banyak aspek yang menjadikan alasan mengapa keamanan nasional adalah sebuah keharusan yang harus dicapai oleh Iran. Di situ disebutkan, bahwa kepemilikan nuklir Iran juga dipacu oleh adanya dua kekuatan nuklir yaitu Israel dan Pakistan; dan adanya pengaruh Amerika Serikat yang makin kuat dalam kawasan terutama setelah Afghanistan dan Irak kalah perang melawan Amerika Serikat dan sekutunya. Meskipun begitu, Iran melihat besarnya ancaman yang diberikan berasal dari Amerika Serikat dan Israel.

Menurut Chubin (2003) Amerika Serikat (AS) dan Israel adalah dua negara yang dianggap memberikan ancaman kepada Iran. Menashri (2003) memiliki kesamaan pendapat dengan Chubin, menurutnya tingkat campur tangan AS yang semakin tinggi di negara Irak dan kawasan timur tengah dalam rangka perang melawan teror merupakan hal yang Iran cermati karena berhubungan dengan keamanan nasionalnya. Lebih lanjut lagi ia menambahkan, bahwa demonstrasi kekuatan AS hanya akan membuat Iran semakin khawatir (Menashri, 2003: 1). 
Lamy dalam Baylis dan Smith (2002) mengatakan, bahwa negara haruslah bersiap menghadapi kemungkinan diinvasi oleh negara lain dalam sistem internasional yang anarki. Iran jelas khawatir akan keadaan yang mungkin terjadi di negaranya seperti terjadi dua negara tetangganya Afghanistan dan Irak; yaitu pergantian Rezim Islam. Tindakan kecenderungan bahwa invasi AS bisa terjadi dikemukakan oleh Dunn (2007), menurutnya:

... Removal of Saddam Hussein was seen not as a one-act play but rather as the opening scene in the total transformation of the greater Middle East. The campaign in Iraq was to be a demonstration of American power so that, as pentagon adviser Richard Perle told an audience not long after the invasion, 'we could deliver a short message, a two word message: "You're next."' And the prime focus for American concern after Iraq was the regime in Tehran. This is illustrated by another remark, lighthearted in tone but no less revealing. At a meeting with the outgoing interim Iraq ambassador General Jay Garner in June 2003, Bush thanked him for doing a 'great job' and slapped him on the back, asking, 'Hay, Jay, you want to do Iran? The response was equally informative of the mood: 'Sir, the boys and I talked about that and we want to hold out for Cuba." (Dunn, 2007: 19).

Sebuah ancaman lisan, terutama apabila datang dari seorang perancang perang Irak adalah sebuah ancaman nyata. Belum lagi ternyata untuk mendukung rencana serangan ini ternyata Amerika Serikat sudah menyiagakan satu pesawat perang B-52 di Turki dan satu kapal induknya di teluk Persia, di tahun 2006 (Dunn, 2007: 21). Ancaman yang berubah nyata sedikit demi sedikit tentunya membuat Iran khawatir.

Masalah bagi Iran terlihat bahwa ancaman utama bagi negara Iran bukan berasal dari negara kawasan yang sama (AS). Julukan Iran bagi AS adalah "Great Satan" dan hal ini sudah diberikan sejak kasus Revolusi Islam Iran sejak tahun 1979 (Vakil, 2006: 52). Memerangi AS adalah sebuah keharusan karena sebelumnya Iran dianggap mengotori dirinya sendiri dengan melakukan westernisasi ketika dinasti Reza Pahlavi berkuasa. Isolasi ekonomi yang dijatuhkan oleh AS kepada Iran sejak 27 tahun yang lalu tidak membuat Iran hancur (Vakil, 2006: 51). Dengan mengambil filosofi dari pemimpin spiritual Iran Khamaeni, setan besar AS bertujuan untuk mengganti semua rezim muslim, merusak Iran, dan mengganggu umat muslim diseluruh dunia (Menashri; 2003: 4). Ketidaksukaan Iran, pada umumnya, sudah tertanam sejak revolusi Islam Iran, dan saat ini, dengan adanya pasukan AS di Irak dan Afghanistan membuat Iran yang secara militer relatif lemah mencari alternatif baru untuk membangun reaktor nuklirnya yang tertunda.

Masyarakat Iran tidak akan lupa kepada sanksi ekonomi yang diusahakan oleh AS dan akhirnya dijatuhkan oleh negara-negara lain yang turut mendukung AS. Iran menyatakan, bahwa tidak menjalin hubungan diplomatik dengan AS adalah 
kebijakan utamanya. Sudah sejak lama Iran tidak begitu peduli dengan keinginan AS di kawasan Timur Tengah yang dianggap ingin melakukan westernisasi. Karenanya ancaman kehadiran AS (lewat invasi Irak dan Afghanistan) yang berada tepat diperbatasan Iran adalah sesuatu yang perlu dicermati dan dikhawatirkan oleh Iran.

Amerika Serikat sendiri dalam buku putih pertahanan yang diluncurkan pada tahun 2006 menyatakan, bahwa AS akan melakukan pendekatan berbeda yaitu preemptive strike. Dunn (2007) kemudian menerangkan lebih lanjut mengenai kebijakan yang diambil ini, yaitu:

In March 2006 the white house published a new version of The National Strategy of the United States of America... This document sets out the US government's duty to anticipate and counter threats, using all elements of national power, before the threats can do grave damage. The greater the threat, the greater the risk of inaction-and the more compelling the case for taking anticipatory action...However the documents does not deal only talking in principle... the report continues by stating that we may face no greater challenge from a single country than from Iran (Dunn, 2007: 20).

Menurut Dunn (2007), AS lebih suka melakukan tindakan yang bersifat mengancam Iran dengan kapabilitas senjata dan pamer kekuatan daripada menggunakan pendekatan lain seperti diplomasi. Melihat kutipan di atas, bisa kita lihat bahwa Iran masuk kedalam rencana kebijakan AS di Timur Tengah, dan hal ini semakin ditekankan oleh Fawcett (2005), bahwa Iran adalah negara poros setan (axis of evi) dan negara yang mengancam (hostile state). Amerika Serikat sendiri memiliki kebijakan preemptive, yaitu menyerang sebelum diserang, hal ini tentu mengkhawatirkan Iran.

Selain tekanan dan ancaman diberikan oleh AS, Iran memiliki ancaman lainnya dari wilayah yang sama yaitu dari Israel. Jika AS disebut sebagai Setan Besar, maka Israel diistilahkan sebagai musuh bebuyutan karena selalu didukung oleh AS dalam semua tindakannya. Hal ini menyiratkan bahwa ancaman dari Israel dan AS sejalan dalam menekan Iran untuk tidak memiliki perangkat pertahanan jika diserang, yaitu nuklir.

Iran sendiri, seperti yang kita ketahui, terus berusaha mengulur waktu agar pembangunan reaktor-reaktor nuklir selesai dan mampu menciptakan nuklir. Meminjam parafrase yang dikatakan Mearsheimer yang dikutip Lamy dalam Baylis dan Smith (2002), dikatakan bahwa negara besar (AS) akan mendukung perlucutan senjata dan potensi nuklir di Iran agar negara yang melakukan perlucutan tersebut lebih mudah untuk diinvasi. Mantan Duta Besar Iran untuk Indonesia, Shaban Saidi Moaddab, pernah mengatakan bahwa jika teknologi nuklir baik untuk AS, maka nuklir juga akan baik untuk Iran (The Jakarta Post, 2005: 01). Sistem internasional yang anarki membuat Iran ingin terus bertahan dan mempertahankan instalasi nuklirnya. 
Seperti yang sudah disebutkan sebelumnya, selain AS, yang memiliki kepentingan agar Iran tidak memiliki nuklir adalah Israel. Seperti yang kita ketahui, bahwa Israel adalah negara yang sangat dilindungi oleh AS. Selain masalah Irak dan Afghanistan, Presiden AS George W. Bush menyatakan, bahwa menjaga Israel agar tetap aman adalah perhatiannya. Selain itu, AS akan mendukung Israel, yang mana Israel adalah musuh Iran, di kawasan Timur Tengah (The Economist, 2008: 13). Pihak Israel sendiri mengancam, bahwa Israel akan menyerang Iran karena kekhawatiran nuklir yang dimiliki oleh Iran akan membuat jarak kekuatan antara kedua negara akan semakin dekat. Israel sendiri tidak merasa ragu-ragu untuk bertindak sendiri, seperti yang mereka lakukan kepada Irak pada saat perang teluk pertama.

Bagi Iran, cara terbaik mengatasi kemungkinan-kemungkinan yang buruk dan bisa saja terjadi, misalkan diinvasi AS, maka memiliki nuklir adalah sebuah hal yang diperlukan. Iran dapat dikategorikan sebagai negara yang tertinggal dalam pengembangan persenjataan militernya. Aspek militer sendiri adalah bagian penting bagi keamanan dan kekuatan nasional. Dan hal ini adalah potensi yang bisa dimiliki dengan kepemilikan senjata nuklir.

\section{Ketertinggalan Aspek Militer Iran sebagai Penunjang Keamanan Nasional}

Waltz (1979) mengatakan, bahwa dalam sistem internasional yang anarki, power dibutuhkan oleh negara agar mampu bertahan. Dikatakan juga, bahwa tujuan akhir negara adalah bertahan (survival), bukan mencapai power. Di sini bisa kita lihat bahwa power adalah cara, bukan tujuan. Hal ini juga yang dilakukan Iran dalam sistem internasional yang seolah-olah dikendalikan oleh AS. Iran bertahan dengan salah satu bentuk power yaitu kekuatan militer.

Semenjak perang teluk pertama, setelah Iran diserang oleh Irak, Iran mengalami kemunduran dalam aspek persenjataan militer. Hal ini disebabkan oleh kerusakan dan kehancuran yang diderita oleh militer Iran karena banyaknya peralatan perang yang hancur. Menurut Anggoro dalam Kartini (2005), Sebanyak 60 persen persenjataan utama Iran, dimana mayoritasnya adalah senjata darat, rusak pada tahun final peperangan dengan Irak (1980). Persenjataan udara, seperti pesawat tempur yang moderen, hanya memiliki kapabilitas operasional yang terbatas. Selain pesawat tempur, kekuatan helikopter tempur yang sangat besar, juga memiliki kendala kapabilitas operasional yang sangat terbatas. Di laut, sangatlah sulit bagi Iran untuk berbicara banyak setelah tidak diperbaharuinya persenjataan laut dalam beberapa tahun terakhir (Anggoro dalam Kartini, 2005: 47).

Saat ini, terutama setelah Irak diinvasi dan terjadi pergantian rezim dari tahun 2003, Iran mendapati posisinya terjepit oleh AS. Iran tentunya merasa khawatir karena apa yang terjadi di Irak bisa terjadi pada mereka. Ketakutan ini diperkuat pernyataan perwakilan Pentagon Richard Perle, yang menyatakan bahwa Iran adalah target berikutnya setelah Irak (Dunn, 2007: 19). Menurut Feldman, 
pernyataan bernada ancaman ini sangatlah signifikan bagi Iran yang sejak selesainya perang dengan Irak belum mampu meningkatkan kapabilitas militernya bahkan sampai tahun 2005 (Feldman dalam Kartini, 2005: 47).

Cara terbaik dan tercepat untuk mempersiapkan kekuatan nasional adalah dengan cara mempercepat instalasi nuklir yang mulai sejak tahun 1995 telah dibangun kembali. Melindungi keamanan nasional lewat instalasi nuklir menjadi prioritas penting untuk mengejar ketertinggalan militer Iran dari negara Timur Tengah lainnya.

Dalam segi militer, kepemilikan nuklir Iran di Timur Tengah akan mempengaruhi negara lain yang berada di sekitarnya. Morgenthau dalam Levine (1986) menyatakan, bahwa nuklir akan memberikan implikasi yang luas bagi negara disekitarnya karena memberikan efek ancaman yang berbeda dengan persenjataan konvensional lainnya. Hal ini membantu Iran memberikan efek deterrence bagi negara pengancamnya dan memberikan banyak waktu untuk mempersiapkan kekuatan militernya sebagai kekuatan nasional (Morgenthau, 1985: 139).

Secara politis, kepemilikan nuklir akan meningkatkan kekuatan politik Iran di Timur Tengah (The Economist, 2008: 29). Negara yang memiliki nuklir akan dianggap sebagai negara yang berada di tingkat atas (top of the table) dalam hubungan internasional (Baylis, 2002: 422). Kepemilikan nuklir membantu untuk mempertinggi posisi tawar Iran dalam hubungan internasional.

Dari segi sosietal, nuklir akan membantu Iran dalam menjaga identitas nasionalnya. Iran memiliki identitas sebagai negara muslim Shiah dimana agama ini adalah minoritas di Timur Tengah (Fawcett, 2005: 154). Masih menurut Fawcett (2005), Iran adalah negara dengan tingkat variasi etnis tertinggi di Timur Tengah. Dengan kebanggaan sebagai negara kuat dengan kepemilikan nuklir, akan mempermudah memperkuat keamanan nasionalnya karena kerusuhan etnis hanya terjadi di negara yang lemah (Buzan, 1991: 122). Buzan (1991) juga menyatakan, bahwa keamanan nasional secara sosietal akan membantu menjaga keamanan nasional dalam jangka panjang.

Dari segi ekonomi, kepemilikan nuklir berguna untuk mengurangi beban konsumsi minyak impor. Meskipun Iran memiliki banyak cadangan minyak bumi tetapi tidak bisa mengolahnya sendiri. Dari produksi 4.1 milyar barel, Iran hanya mampu memproduksi menjadi bahan bakar jadi sebanyak 0.2 milyar barel dari tingkat konsumsi sebesar 1.5 milyar barel (Sahidi dalam Kartini, 2005: 16). Dari angka tadi, kebanyakan digunakan sebagai bahan bakar pembangkit tenaga listrik (Sahidi dalam Kartini, 2005: 12). Bila memiliki nuklir, Iran akan mampu mengurangi kebergantungannya kepada bahan bakar minyak dan berdampak positif dalam jangka panjang.

Dari segi lingkungan, bisa dilihat dari faktor sumber daya yang dimiliki oleh Iran terutama dalam aspek bahan bakar fosil atau minyak mentah. Iran merupakan negara dengan cadangan minyak terbesar ke empat di Timur Tengah. Jumlah cadangan minyak sebesar 89.7 thousand million barrel (Fawcett, 2005: 
80). Dengan memiliki nuklir, ancaman invasi dari negara lain seperti yang AS lakukan kepada Irak bisa ditangkal (Dunn: 2007, 19).

Menurut Buzan (1991), keamanan nasional terdiri dari multi faktor baik yang berupa fisik seperti teritori maupun yang tidak berupa fisik seperti value. Kepemilikan nuklir bagi Iran akan mampu melindungi keamanan nasional mereka dilihat dari lima jenis keamanan menurut Buzan (Keamanan militer, sosietal, politis, ekonomi, dan lingkungan).

\section{Iran: Nuklir dan Detterence}

Seperti yang dibahas sebelumnya oleh Waltz dalam Art dan Jervis (2000), Iran jelas membutuhkan nuklir karena Iran jelas takut kepada kapabilitas militer Amerika Serikat baik sekarang maupun dimasa depan. Iran jelas tertinggal dalam segala aspek persenjataan konvensional dan pada akhirnya memutuskan untuk menyingkat waktu pengembangan kapabilitasnya dengan nuklir.

Tindakan Iran ini sesuai yang dikatakan oleh Spiegel (2004) yang mengatakan, bahwa terdapat tiga hal yang harus dilakukan untuk meyakinkan negara yang dianggap mengancam bahwa negara ini (Iran) serius dalam tindakan deterrence (penangkalan) ini yaitu:

a. Komitmen

Komitmen Iran dalam melakukan penangkalan seperti yang dikemukakan oleh pemimpin spiritual Iran, Khamaeni. Menashri (2003) mengutip pernyataannya bahwa Iran harus bersiap untuk menghadapi setan besar AS dan ditambahkan oleh pernyataan keras Presiden Iran Mahmoud Ahmadinejad, bahwa Israel harus lenyap dari peta dunia. Hal ini memperlihatkan bahwa Iran berkomitmen untuk menjaga keamanan negara mereka dari ancaman musuhnya. Komitmen ini dilaksanakan tanpa memperdulikan tekanan dunia internasional yang meminta Iran menghentikan aktivitasnya melakukan pengayaan uranium. Bahkan ketika Persatuan Bangsa-Bangsa (PBB) memberikan resolusi lewat Dewan Keamanan 1747 yang membuat Iran semakin di kucilkan dari hubungannya dengan barat, Iran tetap tidak bergeming dan melaksanakan apa yang sudah menjadi komitmennya; melindungi negerinya.

b. Kapabilitas.

Iran sadar bahwa kapabilitas mereka untuk melakukan penangkalan masih kurang, karenanya dengan kepemilikan nuklir kapabilitas mereka akan meningkat dengan pesat. Iran terus menggenjot kapabilitas nuklirnya baik lewat riset intensif rudal sebagai pembawa hulu ledak nuklir dan produksi hulu ledak sendiri. Ketika dunia internasional meminta Iran untuk menghentikan pengayaan nuklirnya hal ini tidak dilakukan. Di sini Iran jelas menunjukkan apa yang mereka mampu lakukan dan apa yang akan mereka lakukan kepada dunia internasional. 
c. Kredibilitas

Kredibilitas sangat berhubungan dengan sejarah Iran. Setelah Revolusi Islam Iran pada tahun 1979, Iran secara terang dan jelas menganggap bahwa negara barat (terutama AS dan sekutu utamanya Israel) adalah ancaman terbesarnya. Iran secara terang-terangan tidak suka dengan kebijakan AS terhadap dunia muslim. Sebaliknya AS sendiri tidak meragukan kredibilitas Iran sebagai negara yang menentangnya. Hal ini dikemukakan oleh Dunn (2007) yang mengatakan, bahwa dalam buku tahunan kebijakan pertahanan nasional Iran disebut-sebut dalam buku itu sebagai tantangan yang menghambat kebijakan AS. Selain itu Israel juga sadar bahwa Iran memang kredibel dan muncul sebagai ancaman kebijakan Israel terutama mengenai masalah Palestina.

Dilihat dari persyaratan penangkalan di atas kita bisa melihat, bahwa Iran memenuhi semua persyaratan yang diajukan oleh Kegley (2004). Iran memang berhasrat untuk mempertahankan negeri mereka. Iran memang harus mengejar kekuatan untuk penangkalan agar mampu selamat dalam sistem internasional yang anarki, terutama dengan adanya AS yang mengancam di sekitar mereka (Anggoro dalam Kartini, 2005: 48).

\section{KESIMPULAN}

Segala tekanan yang diperoleh Iran dari dunia internasional tetap tidak mengubah pendirian negara ini untuk mengembangkan pembangunan nuklirnya. Iran, dalam hal ini memiliki ketakutan akan kemungkinan serangan Amerika Serikat. Ketakutan ini memiliki alasan yang cukup kuat, karena inkonsistensi Amerika baik dari segi pernyataan maupun kebijakan luar negerinya. Adanya tindakan Amerika Serikat yang cukup agresif terhadap negara-negara di kawasan Timur Tengah, membuat Iran merasa terancam eksistensinya. Dengan kata lain, pengembangan nuklir di Iran juga bertujuan selain untuk meningkatkan efisiensi sumber daya alam negara tersebut, juga dapat dianggap sebagai peningkatan pertahanan keamanan nasional Iran karena merasa terancam akan hegemoni Amerika Serikat.

Menurut Spiegel (2004), keamanan nasional adalah sesuatu yang tidak terdefinisi, maksudnya siapa saja bisa menggunakan istilah ini untuk berbagi kepentingan. Tetapi satu hal yang pasti diinginkan oleh negara manapun adalah hilangnya ancaman yang mengganggu negara. Wolfers dalam Art dan Jervis (1985) sadar bahwa keamanan nasional membutuhkan jaminan, yaitu kuatnya kekuatan nasional (national power). Negara yang tidak memiliki kekuatan nasional yang kuat tidak bisa mengharap banyak bahwa keamanan nasionalnya akan terjaga, dan Iran sadar akan hal ini.

Iran terus memperkuat kekuatan nasionalnya, terutama dengan riset intensif rudal balistiknya dan pembangunan instalasi nuklir. Seperti yang dibahas sebelumya oleh Morgenthau dan Thompson ( 1985) kekuatan nasional sangat 
diperlukan untuk membuat negara tetap stabil, dan jika negara stabil keamanan nasional juga akan terjaga. Negara tetangga seperti Irak dan Afghanistan memperlihatkan, bahwa negara yang setelah diinvasi akan membuat keamanan nasional negara tersebut rusak. Selain karena adanya pergantian rezim, semua sendi-sendi penunjang negara seperti keamanan ekonomi, keamanan sosial, keamanan politik, keamanan militer, dan keamanan lingkungan tidak terjaga atau bahkan tidak ada.

Sesuai dengan pendapat Steiburner (2000), Iran berani mengambil resiko nuklir karena dianggap sebagai potensi perlindungan. Iran sendiri memperkuat kapabilitasnya dalam kepemilikan rudal nuklir secepatnya. Karena mereka sadar, bahwa senjata haruslah operasional, bukan hanya barang pajangan saja. Hal ini senada dengan pendapat Quinlan (1991) yang menyatakan, bahwa keseriusan sebuah negara yang memiliki nuklir dalam deterence adalah untuk benar-benar meyakinkan bahwa senjata tersebut operasional. Iran menginginkan nuklir sebagai perangkat untuk menangkal (deterence) keinginan negara penyerang, dalam hal ini Amerika Serikat.

\section{DAFTAR PUSTAKA}

\section{Buku}

Art, Robert, dan Robert Jervis, 1985, International politics: Anarchy, force, political economy, and decision making $2^{\text {nd }}$ edition, United States of America: Little Braw and Company.

Art, Robert dan Robert Jervis, 2000, International politics: Anarchy, force, political economy, and decision making $3^{\text {rd }}$ edition, United States of America: Little Braw and Company.

Baldwin, David, 1993, Neorealism and neoliberalism, New York: Columbia University Press.

Bartholomees, J Boone, 2006, U.S. army war college: Guide to national security policy and strategy; $2^{\text {nd }}$ edition, United States of America: Department of National Security and Strategy.

Baylis, John, dan Steve Smith, 2002, The globalization of world politics; $2^{\text {nd }}$ edition, New York: Oxford University Press.

Black, James A, dan Champion DJ., 1976, Methods and issues in social research, New York: John Wiley and Sons Inc. 
Burchill, Scott dan Andrew Linklater, 1996, Theories of international relations, United Kingdom: Macmillan Press Ltd.

Buzan, Barry, 1991, People states and fear; $2^{\text {nd }}$ edition; Pan agenda for international security studies in the post cold war era, New York: Harvester Wheatsheaf

Buzan, Barry, 1987, An introduction to strategic studies military technology and international, London: The MACMILLAN PRESS L TD

Creswell, J.W, 1998, Qualitative inquiry and research design: Choosing among five tradition. California: sage Publication Inc.

Fawcett, Louise, 2005, International relations of the middle east, United Kingdom: Oxford University Press.

Gray, Colin S, 1986, Nuclear strategy and national style, London: Hamilton Press Griffiths, Martin and Terry O'Callaghan, 2002, International relations: The key concepts, London and New York: Wadsworth.

Hough, Peter, 2004, Understanding global security, London: Routledge Jackson, Robert dan George Sorensen, 1999, Introduction to international relations, Denmark: Oxford University Press.

Kartini, Indriana, 2005, Indonesia and Iran's nuclear issue, Jakarta: LIPI Press.

Kegley et all, 2004, World Politics Trend and Transformation; $9^{\text {th }}$ Edition, Belmont: Thomson Wadsworth

Klare, Michael T, dan Daniel C Thomas, 1991, World security; Trends and challenges at centuries end, New York: ST Martin Press.

Kartini, Indriana, 2005, Indonesia and Iran's nuclear issue, Jakarta: LIPI Press. Kegley et all, 2004, World politics trend and transformation; $9^{\text {th }}$ edition, Belmont: Thomson Wadsworth

Levine, Herbert, 1986, The nuclear arms debated, United States: McGraw-Hill. Lieber, Robert, 1991, No common power; Understanding international relations; $2^{\text {nd }}$ edition, United States: HarperCollins Publisher.

Mas'oed, Mohtar, 1994, IImu hubungan internasional: Disiplin dan metodologi, Jakarta :LP3ES. 
Martin Griffiths and Terry O'Callaghan, International relations: The key concepts, 2002, London and New York: Wadsworth.

Maxwell, Joseph A, 2005, Qualitative research design an interactive approach; $2^{\text {nd }}$ edition, United States of America: Sage Publications.

Mearsheimer, John J, 2001, The tragedy of great power politics, United States of America: W.W. Norton and Company Inc.

Morgenthau, Hans dan Thompson, 1985, The politics among nations; The struggle for Power and Peace; Sixth Edition, United States: Random House Inc.

Muhadjir, Noeng, 2000, Metodologi penelitian kualitatif, Yogyakarta: Rake Sarasin. Nye, Joseph, 2004, Soft power; The means to success in world politics, New York: Public Affairs.

Pettiford, Lloyd dan Jill Steans, 2001, International relations perspectives and themes, England: Pearson.

Smith, Steve, 2006, New dimension in international security, presentation to the IDSS Asia-Pacific programme for senior military officers, Singapura: Sentosa Island.

Spiegel et all, 2004, World politics in a new era, United States: Thomson Wadsworth.

Sugiyono, 2005, Memahami penelitian kualitalif, Bandung: ALFABETA.

Ullman, Robert. 1983, Redefining security, United States: International security.

Usman, Husaini, dan Purnomo Setiady Akbar, 1995, Metodologi penelitian sosial, Jakarta: Bumi Aksara.

Walliman, Nicholas, 2004, Your undergraduate dissertation; The essential guide for success, London and New Delhi: SAGE Publications.

Waltz, Kenneth, 1979, Theory of international politics, United States: AddisonWesley Publishing Company.

Yani, Yanyan M, dan Anak Agung Banyu Perwita, 2005, Pengantar iimu hubungan internasional, Handung: Rosdakarya.

\section{Artikel dalam Jurnal}

"Briefing Iran's nuclear program; As the enrichment machines spin on", The economist, Februari 2008. 
David Hasting Dunn, "Real men want to go to Teheran: Bush, pre-emption and the Iranian nuclear challenge", International affairs, Volume 83 Number 1, January 2007, published by Chatham House.

Quinlan, Michael, 1991, "Nuclear weapons and the abolition of war", International affairs, No 2, Vol 67.

\section{Ensiklopedia}

Microsoft Encarta 2004

Wikipedia

\section{Jurnal Elektronik}

Croft, Stuart, 2006, Images and imaginings of security, United Kingdom: SAGE Publications.

Menashri, David, 2003, Iran after the fall of Baghdad: Implications for western foreign and security policy, Germany: International Policy Analyses Unit.

Orlov, Vladimir, dan Alexander Vinnikov, 2005, The great guessing game: Russia and the Iranian nuclear issue, United States: The Center for Strategic and International Studies and the Massachusetts Institute of Technology.

Chubin, Shahram, dan Robert Litwak, 2003, Debating Iran's nuclear aspiration, United States: The Center for Strategic and International Studies and the Massachusetts Institute of Technology.

Vakil, Sanam, 2006, Iran: Balancing east against west, United Stated: The Center for Strategic and International Studies and the Massachusetts Institute of Technology.

Steinburner, John, 2000, Renovating Arms Control Trough Reassurance, United States: The Center for Strategic and International Studies and the Massachusetts Institute of Technology

\section{Surat Kabar}

The Jakarta Post, 29 April 2005, Unilateral approach may not solve Iran nuke issue: RI, hal 1.

\section{Internet}

www.bbc.co.uk/iran/4688984.stm.htm. diakses 23 April 2007. 